\title{
Breast Capillary Hemangioma
}

National Cancer Institute

\section{Source}

National Cancer Institute. Breast Capillary Hemangioma. NCI Thesaurus. Code C5210.

A capillary hemangioma arising from the breast. 